\title{
Peripheral arthropathies in inflammatory bowel disease: their articular distribution and natural history
}

T R Orchard, B P Wordsworth, D P Jewell

\begin{abstract}
Background-Peripheral arthropathy is a well-recognised complication of inflammatory bowel disease (IBD). Little is known of its natural history, but a variety of joint involvement has been described, from large joint pauciarticular arthropathy to a rheumatoid pattern polyarthropathy.

Aims-To classify the peripheral arthropathies according to pattern of articular involvement, and study their natural history and clinical associations.

Methods-The case notes of all patients attending the Oxford IBD clinic were reviewed, and information on general disease characteristics, extraintestinal features, and arthropathy extracted. This was confirmed by direct patient interview using questionnaires at routine follow up. Patients with recorded joint swelling or effusion were classified as type 1 (pauciarticular) if less than five joints were involved and type 2 (polyarticular) if five or more were involved. Patients without evidence of swelling were classified as arthralgia.
\end{abstract}

Results-In total, 976 patients with ulcerative colitis (UC) and 483 with Crohn's disease (CD) were reviewed. Type 1 occurred in $3.6 \%$ of patients with UC (83\% acute and self-limiting) and in $6.0 \%$ of those with CD (79\% self-limiting); $83 \%$ and $76 \%$, respectively, were associated with relapsing IBD. Type 2 occurred in $2.5 \%$ of patients with UC and $4.0 \%$ of those with CD; $87 \%$ and $89 \%$, respectively, caused persistent symptoms whereas only $29 \%$ and $42 \%$, respectively, were associated with relapsing IBD.

Conclusion-Enteropathic peripheral arthropathy without axial involvement can be subdivided into a pauciarticular, large joint arthropathy, and a bilateral symmetrical polyarthropathy, each being distinguished by its articular distribution and natural history.

(Gut 1998;42:387-391)

Keywords: ulcerative colitis; Crohn's disease; peripheral arthropathy; extraintestinal manifestations

Locomotor complications are well-recognised in both ulcerative colitis and Crohn's disease. They include peripheral and axial syndromes and are generally considered to be part of the wider group of seronegative spondylo- arthropathies, ${ }^{1-3}$ including idiopathic ankylosing spondylitis, reactive arthritis and psoriatic arthritis.

Idiopathic ankylosing spondylitis is characterised by axial skeletal involvement with ankylosis, but peripheral joint involvement may also occur. It is associated with possession of HLAB27 in over $90 \%$ of cases. ${ }^{4}$ Ankylosing spondylitis may also complicate inflammatory bowel disease (IBD), but here the strength of the HLA-B27 association is reportedly less (50$70 \%$ of cases)..$^{5-7}$ Isolated sacroiliitis (which may be asymptomatic) has also been described in IBD, but no association with B27 is recognised in these patients.

The peripheral arthropathies associated with IBD occur in between 5 and $20 \%$ of patients ${ }^{8-11}$ and several patterns of joint involvement have been described, ranging from a large joint pauciarticular arthropathy to a small joint symmetrical polyarthropathy. The proportion of each differs between studies. ${ }^{8-10}$ They are seronegative and are non-erosive and usually non-deforming, but their clinical course and long term outcome have been poorly characterised. ${ }^{9}{ }^{12}$ In addition, no association has been shown between peripheral arthropathies and HLA-B27 in IBD ${ }^{613}$ despite apparent similarities between the large joint arthropathy and post-dysenteric reactive arthritis (in which $70 \%$ of patients are HLA-B27 positive). ${ }^{15}$

Oxford, UK, is a major secondary and tertiary referral centre for IBD and has a large patient population. In this study we have identified all patients with peripheral joint symptoms in the absence of axial disease who attend the Oxford IBD clinic. We have studied the natural history of the peripheral joint disease and the associations with other extraintestinal manifestations and bowel disease in relation to pattern of articular involvement. We have analysed the long term history of peripheral joint involvement in IBD.

\section{Methods}

The case notes of all patients attending the IBD clinic in Oxford were reviewed, and information on the general nature of the bowel disease (diagnosis, age at diagnosis, disease extent, surgery), extraintestinal manifestations (erythema nodosum, uveitis, pyoderma gangrenosum), the presence of psoriasis, and arthropathy was abstracted. The pattern of articular involvement, presence of joint swelling or effusion, duration of symptoms, number of episodes, and presence of lower back pain
Dr Jewell.

Accepted for publication 31 October 1997 
Table 1 General characteristics of the inflammatory bowel disease population

\begin{tabular}{lll}
\hline & Ulcerative colitis & Crohn's disease \\
\hline No of patients & 976 & 483 \\
M:F ratio & $484: 492$ & $202: 281$ \\
Median (range) & $10.7(0.03-64.3)$ & $10.2(0.03-57.4)$ \\
$\quad$ follow up (y) & $9(0.9 \%)$ & $27(5.6 \%)$ \\
Erythema nodosum & $30(3.1 \%)$ & $31(6.4 \%)$ \\
Uveitis & $5(0.5 \%)$ & $6(1.2 \%)$ \\
Pyoderma & & \\
$\quad$ gangrenosum & & \\
\hline
\end{tabular}

Table 2 Disease extent in ulcerative colitis and Crohn's disease

\begin{tabular}{lc}
\hline IBD type & Number (\%) \\
\hline Ulcerative colitis & $308(31.6)$ \\
Rectum only & $375(38.5)$ \\
Distal to splenic flexure & $55(5.6)$ \\
Subtotal colitis & $236(24.3)$ \\
Total colitis & \\
Crohn's disease & $150(31.1)$ \\
Colitis only & $103(21.3)$ \\
Ileocolonic & $193(40.0)$ \\
Terminal ileum \pm caecum & $17(3.5)$ \\
Proximal small bowel only & $20(4.1)$ \\
Extensive small and large bowel & \\
\hline
\end{tabular}

were recorded. Coincident joint disease such as seropositive rheumatoid arthritis, psoriatic arthritis, osteoarthritis, and gout were also noted. In addition, all patients attending the IBD clinic answered a direct questionnaire administered at routine follow up visits in the outpatient clinic in order to validate the case note findings.

Patients with known ankylosing spondylitis (New York criteria), ${ }^{16}$ sacroiliitis or symptoms suggestive of inflammatory back pain were excluded from analysis of peripheral arthropathies, as were patients with coincident joint disease which might have accounted for their symptoms. The remaining patients with peripheral joint symptoms were classified according to the number of joints involved at any one time and the presence of swelling or effusion as:

(1) type 1 (pauciarticular) arthropathy included those with fewer than five joints involved with evidence of joint swelling or effusion;

(2) type 2 (polyarticular) arthropathy included those with five or more joints involved with evidence of joint swelling or effusion.

Definitions of pauciarticular and polyarticular were chosen in line with standard rheumatological definitions. Patients with ill-defined joint symptoms or symptoms without objective evidence of joint swelling or effusion were classified as having arthralgia and were not analysed further.

Table 3 foint complications in inflammatory bowel disease

\begin{tabular}{lcc}
\hline & Ulcerative colitis & Crohn's disease \\
\hline $\begin{array}{l}\text { Type 1 peripheral } \\
\text { arthropathy }\end{array}$ & $35(3.6)$ & $29(6.0)$ \\
$\begin{array}{l}\text { Type 2 peripheral } \\
\text { arthropathy }\end{array}$ & $24(2.5)$ & $20(4.0)$ \\
Arthralgia & $52(5.3)$ & $62(14.3)$ \\
Ankylosing spondylitis & $9(0.9)$ & $6(1.2)$ \\
Inflammatory back pain & $34(3.5)$ & $42(8.7)$ \\
& & \\
Total & $154(15.8)$ & $159(32.9)$
\end{tabular}

Data are expressed as number (\%).
The natural history, articular distribution and occurrence of other complications were then compared to test the hypotheses that type 1 and type 2 arthropathies differ in their time course and that the frequency of other extraintestinal features differ between those with and without arthropathy. The significance of differences between the groups was tested using $2 \times 2$ contingency tables and the $\chi^{2}$ test with Yates's correction.

\section{Results}

Tables 1 and 2 show the general characteristics of the IBD population. Only three patients with ulcerative colitis and one with Crohn's disease were diagnosed as having psoriasis. Coincident joint disease was present in 83 patients with ulcerative colitis and 21 with Crohn's disease, and included osteoarthritis, seropositive rheumatoid arthritis, gout, lumbar disc problems, and trauma. Rheumatoid factor was checked in $82 \%$ of patients with type 2 arthropathy and was negative in all cases. In both groups of peripheral arthropathy no patients had destructive bony lesions and the clinical course was not compatible with either rheumatoid or crystal arthropathies, and none of the patients required joint replacement. Table 3 shows the prevalence of joint disease related to the IBD. Figures for inflammatory back pain and ankylosing spondylitis are included for the sake of completeness but were not analysed in the context of peripheral arthropathies. Women were significantly more likely to develop both type $1 \quad(p=0.009)$ and type 2 arthropathy $\left(\mathrm{p}=2.3 \times 10^{-5}\right)$. Ankylosing spondylitis occurred in $0.9 \%$ of patients with ulcerative colitis and $1.2 \%$ of those with Crohn's disease, $50 \%$ of whom had peripheral joint involvement. The median length of follow up of patients with peripheral arthropathy (10.1 years in ulcerative colitis and 10.3 years in Crohn's disease) was similar to that of the population as a whole (10.7 years in ulcerative colitis and 10.2 years in Crohn's disease).

In a small number of cases the arthropathy either predated the diagnosis of IBD or was present at the time of diagnosis. In type 1 arthropathy five $(14 \%)$ of 35 patients with ulcerative colitis and three $(10 \%)$ of 29 with Crohn's disease had an acute self-limiting arthropathy 10-36 months before diagnosis. In a further six $(17 \%)$ of 35 with ulcerative colitis and four (14\%) of 29 with Crohn's disease it was present at the time of diagnosis. Type 2 arthropathy was rarely apparent before diagnosis in ulcerative colitis $(n=1)$ or at the time of diagnosis $(n=1)$. Two $(10 \%)$ of 20 patients with Crohn's disease developed the arthropathy before diagnosis and in a further five $(25 \%)$ it was present at the time of diagnosis. Most patients, therefore, developed the joint complications after the diagnosis of IBD had been made, and overall the likelihood of developing the joint complications did not increase with the length of follow up.

Figure 1 shows the distribution of the peripheral arthropathies. Type 1 arthropathy was asymmetrical in $80 \%$ of patients with ulcerative colitis and in $76 \%$ of those with 


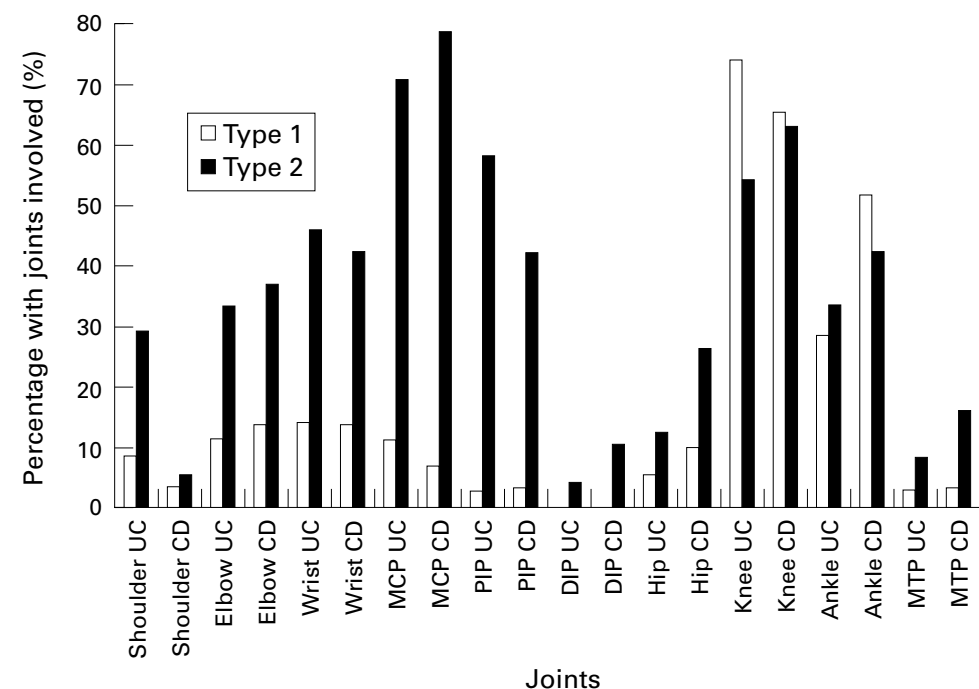

Figure 1 Articular distribution of peripheral arthropathies in inflammatory bowel disease. UC, ulcerative colitis; CD, Crohn's disease; MCP, metacarpophalangealjoint; PIP, proximal interphalangeal joint; DIP, distal interphalangeal joint; MTP, metatarsophalangeal joint.

Crohn's disease. By contrast, type 2 arthropathy was symmetrical in $83 \%$ of patients with ulcerative colitis and $79 \%$ of those with Crohn's disease - a significant difference for both diseases with at $\mathrm{p}=5.9 \times 10^{-6}$ in ulcerative colitis and $\mathrm{p}=0.0006$ in Crohn's disease. The most commonly affected joint in type 1 arthropathy was the knee for both ulcerative colitis and Crohn's disease; the small joints of the hands were very rarely involved. In type 2 arthropathy the metacarpophalangeal joints

Table 4 Natural history of types 1 and 2 peripheral arthropathies

\begin{tabular}{|c|c|c|c|c|}
\hline & \multicolumn{2}{|l|}{ Type 1} & \multicolumn{2}{|l|}{ Type 2} \\
\hline & $\begin{array}{l}\text { Ulcerative } \\
\text { colitis }\end{array}$ & $\begin{array}{l}\text { Crohn's } \\
\text { disease }\end{array}$ & $\begin{array}{l}\text { Ulcerative } \\
\text { colitis }\end{array}$ & $\begin{array}{l}\text { Crohn's } \\
\text { disease }\end{array}$ \\
\hline No of patients & $35(21 \mathrm{~F})$ & $29(22 \mathrm{~F})$ & $24(18 \mathrm{~F})$ & $19(18 \mathrm{~F})$ \\
\hline Symptoms with gut relapses & $30(83)^{\star}$ & $22(76) \dagger$ & $7(29)$ & $8(42)$ \\
\hline Acute self-limiting episodes & $30(83) \ddagger$ & $23(79) \S$ & $3(13)$ & $2(11)$ \\
\hline \multicolumn{5}{|l|}{ No of episodes } \\
\hline 1 & 22 & 13 & 1 & 2 \\
\hline 2 & 6 & 2 & 2 & 0 \\
\hline 3 & 2 & 2 & 0 & 0 \\
\hline$>3$ & 0 & 4 & 0 & 0 \\
\hline \multicolumn{5}{|l|}{$\begin{array}{l}\text { Median (range) duration of } \\
\text { episodes (weeks) }\end{array}$} \\
\hline Persistent symptoms & $5(17)$ & $6(21)$ & $21(87)$ & $17(89)$ \\
\hline $\begin{array}{l}\text { Median (range) duration of } \\
\text { symptoms (months) }\end{array}$ & $10(4-240)$ & $10(6-48)$ & $36(4-276)$ & $36(6-180)$ \\
\hline
\end{tabular}

Data are expressed as number (\%) unless otherwise stated.

${ }^{\star} \mathrm{p}=1.2 \times 10^{-5} ; \mathrm{tp}=0.040 ; \neq \mathrm{p}=2.6 \times 10^{-8} ; \mathrm{g} \mathrm{p}=1.2 \times 10^{-7}$.

Table 5 Associations with other features of disease

\begin{tabular}{lcll}
\hline & No joint problems & Type 1 arthropathy & Type 2 arthropathy \\
\hline Ulcerative colitis & & & \\
No of patients & 830 & 35 & 24 \\
Erythema nodosum & $4(0.5)$ & $6(8.6)^{\star}$ & $1(4.2)$ \\
Uveitis & $10(1.2)$ & 0 & $4(16.7) \ddagger$ \\
Pyoderma & $4(0.5)$ & $6(17.2)$ & $1(4.2)$ \\
$\quad$ gangrenosum & $81(9.7)$ & 29 & $4(16.7)$ \\
Surgery & 339 & $7(24.1) \S$ & 19 \\
Crohn's disease & $7(2.1)$ & $5(17.2) \uparrow$ & 0 \\
No of patients & $9(2.9)$ & $1(3.4)$ & $5(26.3) \star \star$ \\
Erythema nodosum & $5(1.5)$ & $6(20.7)+\dagger$ & 0 \\
Uveitis & $192(56.8)$ & & $8(42.1)$ \\
Pyoderma & gangrenosum & &
\end{tabular}

Data are expressed as number $(\%)$.

${ }^{\star} \mathrm{p}=2.0 \times 10^{-5} ; \mathrm{tp}=9.6 \times 10^{-9} ; \neq \mathrm{p}=1.2 \times 10^{-7} ; \rrbracket \mathrm{p}=5.0 \times 10^{-8 ;} \uparrow \mathrm{p}=0.000592 ;{ }^{\star \star} \mathrm{p}=5.1 \times 10^{-6 ;}+\mathrm{tp}$ $=8.3 \times 10^{-5}$.
(MCP) were most commonly involved, but a wide variety of other joints were also affected.

Table 4 shows the natural history of the peripheral arthropathies. Type 1 is significantly more likely to be associated with relapsing IBD than type 2 for both ulcerative colitis and Crohn's disease. Similarly type 1 occurs significantly more often as acute, self-limiting episodes than type 2 in ulcerative colitis $(83 \%$ v $\left.13 \%, \mathrm{p}=2.6 \times 10^{-8}\right)$ and Crohn's disease $(79 \%$ $\left.v 11 \%, \mathrm{p}=1.2 \times 10^{-7}\right)$. These episodes always lasted for less than 10 weeks and resulted in resolution of the joint symptoms. However, the number of episodes was higher in Crohn's disease: four patients with Crohn's disease had more than three episodes, whereas none of the patients with ulcerative colitis had more than three. Type 2 arthropathy generally had more persistent symptoms, lasting for a median of three years in both ulcerative colitis and Crohn's disease.

The distribution of gut involvement in ulcerative colitis was the same in patients with and without arthropathy. In Crohn's disease there was a trend towards more colonic involvement with type 1 arthropathy but this was not statistically significant.

The joint disease required treatment in the vast majority of cases (97\% of type 1 and $95 \%$ of type 2). Twenty per cent of patients with both types of arthropathy required only simple analgesia. However, $40 \%$ of patients with type 1 and $55 \%$ with type 2 arthropathy required treatment with non-steroidal antiinflammatory drugs (NSAIDs), and in three cases of type 1 arthropathy this preceded the onset of gut symptoms. A large proportion of patients also received glucocorticoid treatment (27\% with type 1 and $25 \%$ with type 2 ). Sulphasalazine has been used widely in spondyloarthropathies, but as most patients were already taking it for IBD, its symptom modifying effects were impossible to analyse in IBD arthropathy.

There was a significant association between type 1 arthropathy and erythema nodosum and uveitis in either ulcerative colitis or Crohn's disease, and an association between type 2 and uveitis only (table 5). There was a trend towards increased surgery in patients with arthropathy and ulcerative colitis which was significant for type 1 if patients who developed the arthropathy after ileal pouch surgery were included $(p=0.013)$. In contrast, patients with Crohn's disease and type 1 arthropathy were significantly less likely to require surgery $(\mathrm{p}=0.0004)$. We felt that this could represent a difference in disease distribution in the gut between patients with and without joint disease. However, there was no significant difference in disease extent in either ulcerative colitis or Crohn's disease between those with and without arthropathy.

\section{Discussion}

This study shows that peripheral arthropathy is a relatively common complication of IBD that frequently requires modification of treatment and often the use of anti-inflammatory drugs which may themselves influence the bowel dis- 
ease. It also suggests that it is reasonable, on clinical grounds, to subdivide the enteropathic peripheral arthropathy associated with IBD according to the criteria in the box.

\section{Classification of enteropathic peripheral arthropathy}

Type 1 (pauciarticular)

- Less than 5 joints

- Acute, self-limiting attacks ( $<10$ weeks)

- Often coincides with relapses of IBD

- Strongly associated with extraintestinal manifestations of IBD

Type 2 (polyarticular)

- Five or more joints

- Symptoms usually persist for months to years

- Runs a course independent of IBD

- Associated with uveitis but not with other extraintestinal manifestations

Clinically type 1 arthropathy is similar to postdysenteric reactive arthritis, with most patients having self-limiting disease but about $20 \%$ going on to develop persistent problems. ${ }^{17}$ The arthropathy is commonly associated with an acute relapse of the IBD and responds to treatment with steroids and NSAIDs. In a few cases treatment with NSAIDs started before the acute relapse, raising the possibility that in a minority of cases ingestion of NSAIDs might have been responsible for the subsequent relapse. Type 1 arthropathy is also strongly associated with other extraintestinal manifestations, such as erythema nodosum and uveitis.

The natural history and clinical associations of type 2 arthropathy are different, particularly if those patients with acute, self-limiting joint disease are ignored (these account for two of the four cases of uveitis and one of the cases of erythema nodosum in ulcerative colitis, and they all involved a large joint). Similarly in Crohn's disease this group accounted for one of the cases of uveitis. This suggests that either they were incorrectly categorised owing to inclusion of painful joints that were not swollen, and therefore were not part of the arthropathy (that is, coexisting type 1 arthritis and arthralgia) or that there may be a degree of overlap between the two syndromes. In support of this second possibility one patient who initially had a typical type 1 arthropathy subsequently developed a significant polyarthropathy with joint swelling. Although both types of arthropathy normally presented after the diagnosis of IBD had been made, $31 \%$ of the type 1 arthropathies in ulcerative colitis and $24 \%$ in Crohn's disease presented at or up to three years before the time of diagnosis. Recent studies have suggested that $6 \%$ of patients with a seronegative spondyloarthropathy will develop IBD, but that patients with normal gut histology at the time of the arthropathy do not go on to develop IBD. ${ }^{18}{ }^{19}$ It would therefore seem good clinical practice to obtain a rectal biopsy sample from all patients presenting with an acute "reactive" arthritis, particularly if associated with diarrhoea, and further gut investigation should be pursued if the bowel disturbance is persistent. Type 2 arthropathy predated the diagnosis of Crohn's disease in two patients but the diagnosis was made within six months as part of a general clinical work up.

Previous studies of peripheral arthropathy in IBD have failed to show any link with possession of HLA-B27, ${ }^{61314}$ but the numbers were small and all the cases of peripheral joint disease were regarded as a single entity, whereas our study suggests the two arthropathies should be considered separately. In the context of other seronegative arthritides the similarity between type 1 arthropathy in this study and reactive arthritis would suggest that a link to HLA-B27 is likely. In contrast type 2 arthropathy seems to be a distinct entity.

We feel that the cause of IBD is likely to be an interaction between genetic susceptibility and environmental factors. ${ }^{20}$ It is also probable that there is genetic heterogeneity within the disease that defines its phenotypic characteristics, ${ }^{20} 21$ although defining the precise phenotypic links has been difficult. This study demonstrates the existence of two distinct forms of peripheral arthropathy in IBD that can be distinguished by a simple classification. Use of this system may help to predict the clinical course of the joint disease and may be used as the basis of further studies of its aetiology.

Dr Orchard is supported by a grant form the National Association for Crohn's and Colitis (NACC).

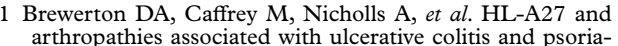
arthropathies associated with
sis. Lancet 1974;i:956-957.

2 Amor BA, Toubert A. Reactive arthropathy, Reiter's syndrome and enteric arthropathy in adults. In: Maddison PJ, Isenberg DA, Woo P, eds. Oxford textbook of rheumatology. Oxford: Oxford University Press, 1993:699-709.

3 Leirisalo-Repo M. Enteropathic arthritis, Whipple's disease, uvenile spondyloarthropathy, uveitis and SAPHO syndrome. Curr Opin Rheumatol 1995;7:284-9.

4 Brown MA, Pile KD, Kennedy LG, et al. HLA class I associations of ankylosing spondylitis in the white population in the United Kingdom. Ann Rheum Dis 1996;55:268-70.

5 Mielants H, Veys EM. HLA-B27 related arthritis and bowel inflammation: I. Sulfasalzine in HLA-B27 related arthritis.
f Rheumatol 1985;12:287-93.

6 Mallas EG, Mackintosh P, Asquith P, et al. Histocompatibility antigens in inflammatory bowel disease. Gut 1976;17: 906-10.

7 Enlow RW, Bias WB, Arnett FC. The spondylitis of inflammatory bowel disease. Evidence for a non-HLA linked axial arthropathy. Arthritis Rheum 1980;23:1359-65.

8 Edwards FC, Truelove SC. The course and prognosis of ulcerative colitis. Part III. Gut 1964;5:1-15.

9 Wright V, Watkinson G. The arthritis of ulcerative colitis. BMf 1965;2:670-5.

10 Greenstein AJ, Janowitz HD, Sachar DB. The extraintestinal complications of Crohn's disease and ulcerative colitis: a study of 700 patients. Medicine (Baltimore) 1976;
55:401-12.

Moll JM. Inflammatory bowel disease. In: Panayi GS, ed. Clinics in rheumatic diseases. Philadelphia: WB Saunders, 985:87-105.

12 Gravalese EM, Kantrowitz FG. Arthritic manifestations of inflammatory bowel disease. Am $\mathcal{F}$ Gastroenterol 1988;83: 703-9.

13 Dekker-Saeys BJ, Meuwissen SGM, Van Den Berg-Loonen EM, et al. Prevalence of peripheral arthritis, sacroiliitis, and ankylosing spondylitis in patients suffering from inflammatory bowel disease. Ann Rheum Dis 1978;37:33-5.

14 Russell AS, Percy JS, Schlaut J, et al. Transplantation antigens in Crohn's disease. Dig Dis 1975:20:359-61.

15 Brewerton DA, Caffrey M, Nicholls A, et al. Reiter's disease and HL-A27. Lancet 1973;ii:996-8.

16 Bennett PH, Burch TA. New diagnostic criteria. New York symposium on population studies in the rheumatic diseases. Bulletin on Rheumatic Diseases 1967:453-8.

17 Calin A, Fries JF An “experimental” epidemic of Reiter's syndrome revisited. Ann Intern Med 1976;84:564-6.

18 Mielants H, Veys E, de Vos, M, et al. The evolution of spondyloarthropathies in relation to gut histology. I. Clinical aspects. F Rheumatol 1995;22:2266-72. 
19 Mielants H, Veys E, Cuvelier C, et al. The evolution of spondyloarthropathies in relation to gut histology. II. Relation between gut and joint. F Rheumatol 1995;22:2279-84.

20 Satsangi J, Grootscholten C, Holt H, et al. Clinical patterns of familial inflammatory bowel disaese. Gut 1996;38:738-41.
21 Satsangi J, Welsh KI, Bunce M, et al. Genetics of inflammatory bowel disease: genes of the major histocompatibility complex are important determinants of susceptibility and disease phenotype in ulcerative colitis, but not in Crohn's disease. Lancet 1996;347:1212-21.

\section{Call for Patients with Familial Pancreatic Disease: The EUROPAC Register}

We are establishing a national UK register (EUROPAC) of families with hereditary pancreatitis, familial pancreatic cancer and where pancreatic cancer has occurred as part of a familial cancer syndrome. This collaboration in Liverpool is between the Department of Clinical Genetics ( Dr Ian Ellis) and the Academic Department of Surgery (Professor John Neoptolemos). The data and samples are collected by behalf of ESPAC (the European Study Group for Pancreatic Cancer), Professor Markus Büchler, Berne, and Professor Hans Beger, Ulm. The study will collaborate with Dr David Whitcomb of the Midwest Multicenter Pancreatitis study group in the United States. We aim to recruit families who are prepared to donate blood for DNA studies. We hope to gain a clearer understanding of the genetic relationship between hereditary pancreatitis and familial pancreatic cancer, and develop screening protocols for individuals at risk.

Hereditary pancreatitis is associated with a mutation in the recently identified cationic trypsinogen gene. This mutation renders the enzyme active within the pancreas, leading to autodigestion. Individuals with recurrent pancreatitis have a greatly increased risk of developing pancreatic cancer, and there is some evidence that DNA analysis of cells from pancreatic fluid may be valuable in detecting premalignant changes which can predict the development of pancreatic adenocarcinoma.

The criteria for inclusion in the study are as follows:

- Hereditary pancreatitis: Three relatives with chronic pancreatitis in the absence of ethanol dependence, hypercalcaemia, or an obstructive cause.

- Familial pancreatic cancer: Two first degree relatives with pancreatic adenocarcinoma. Three or more relatives with pancreatic ductal adenocarcinoma. Pancreatic ductal adenocarcinoma in any two relatives where the sum of their ages is less than 110 years.

- Other familial cancer syndromes: A single documented pancreatic ductal adenocarcinoma in any family with an established familial cancer syndrome-for example, BRCA2, FAMMM, A-T, HNPCC, or FAP.

If you know of any suitable families who may be interested in joining the study, please contact: Fiona McRonald, Clinical Genetics, Alder Hey Children's Hospital, Eaton Road, Liverpool L12 2AP. Tel: 01512525905.

Thank you for your help. 